\title{
A influência da alimentação verde na postura (*)
}

\author{
W, R. JARDIM e A. P. TRIVELIN
}

Escola Superior de Agricultura "Luiz de Queiroz" Untverstdade de sao Paulo

\section{fNDICE}
1) Introdução
452
2) Material e Método ..... 453
4) Agradecimento ...... 456
3) Resumo e Conclusöe
455
5) Abstract $\ldots \ldots \ldots \ldots \ldots \ldots 757$
6) - Bibliografia $\ldots \ldots \ldots \ldots \ldots 457$

(*) Trabalho da Seção de Avicultura e Cunicultura. 


\section{1) INTRODUUÇAO}

O presente trabalho diz respeito ao comportamento da galinha com relação a sua postura em face de uma alimentaçăo verde. sabido que numa população avicola, a elevada postula está na dependencia de muitos fatores. (tratamento, saúde, idade, estação do ano, qualidades genéticas) e sujeita também a influencia direta de uma alimentaça adequada e completa, ou seja, portadora de todos as elementas requeridos para :ua manutenção e formação dos ovos.

A alimentação verde para as galinhas constitui um alimento secundário e complementar (4) contudo, năo deixa de ter importancia. Embora contenha menor quantidade de prinć́pios nutritivos quaando comparada ao alimento concentrado, tem influencia na digestáo,- na vitalidade des animpis, grạ̧as às suas propriedades laxativas e estimulantes do apetite $(3,4$, $5,6)$ e ainda devido a sua riqueza em sais minerais e vitaminas. Ao lado dessas propriedades, a alime traça vèrde concorre ainda para evitar a engorda excessiva; finalmente admite-se que favoreça a postura $(2,4,8)$.

Durante o crescimento das aves, sempre há necessidade de administrar-lhes allmentos verdes (7), afim de atender às exigências de desenvolvimento a para compensar as deficiencias relativas dos cereais em yitaminas e minerais. Para aves adultas, talvez venham os alimentos verdes agir mais propriamente pelas suas fibras (celulose), facilitando a digestão dos concentrados, do que, como um alimento capaz de afetar sobremodo a postura das aves.

Náo congitamos aqui da germinabilidade dos ovos ou sanidade das aves quando submetidas a um regime de carencia de verde porque tals assuntos deveráo constituir objeto de novas pesquisas.

Para o ensaio em questáo, utilizamos galinhas da raça Rhode Island Red, já adultas e sujeitas a uma alimentaçăo balanceada, calculada portanto do ponto de vista da necessidade dessas poedeiras e na qual supunha-se conter suficiente quantidade de caroteno devido a proporçáo alta de milho amarelo.

O objetivo único déste trabalho foi a verificaçăo da afirmativa que se encontra nalguns livros de Avicultura que as galinhas, quando submetidas a uma alimentaça abundante de 
verdura, aumentam a postura, como pretendem diversos autores e práticos.

\section{2) MATERIAL E METODO}

Em 10 parques com 10 cabeças cada um, foram reunidas 100 aves, constituindo os dois lotes da experiência : o lote $A$ numerado de 1 a 5 e o lote $B$, de 6 a: 10. Os ovos eram recolhidos diàriamente, devidamente marcados com o número da galinha para ulterior apreciaçáo.

Durante um perfodo de 16 dias, o lote A foi submetido a um regime sem verdura, enquanto que o lote $B$, durante o mesmo período, sujelto à mesma raçáo, esteve sob farta alimentaçăo verde. O tratamento no segundo período foi.justamente 0 inverso, isto é, durante os 30 dias consecutivos ao primeiro período, o lote $A$ passou a receber alimento verde, o qual foi suprimido no lote $B$. Assim, no lote $A$, as aves passaram de um periodo sem verdura para o com verdura, e no lote $B$ dum regime com verdura para outro sem verdura.

No fim do 46.0 dia de experiência, pudemos constatar que algumasi aves tiveram postura muito irregular è de posse desses dados foram considerados dois casos: (1) admitindo todas as aves, independentemente de qualquer irregularidade e (2) eliminando todas aquelas que apresentaram semelhante comportamento.

O quadro 1 encerra os dados resultantes da análise dos 2 lotes para o primeiro caso. Observa-se por ele que a média da postura no lote $A$, diminulu do primeiro para o segundo periodo, ou seja, de 5,21 para 4,77 ovos diários, o mesmo se dando para o Ióte $B$, que baixou de 6,27 para 6,17 . No quadro 2 estao expressọs as resultạos de $t$, dạ compárăçăo das médiạ, num mesmo lote, entre o tratamento com verdura e sem verdura, e entre os lotes, sob o mesmo tratamento:

Para ambos os lotes ( $A$ e $B$ ) os valores de $t$ entre os tratamentos mostraram-se estatisticamente insignificantes, indicando a nenhuma influencia do verde na postira. Já entre os lotes, sob o mesmo tratamento os valores de $t$ foram signilfcantes, revelando serem eles constituidos de aves diferentes na aptidso: postura: 


\section{QUADRO 1}

\begin{tabular}{|c|c|c|c|c|c|c|}
\hline Lotes & Tratamento & 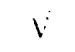 & $\because n$ & $\pm \theta^{\theta}$, & $\because n 1$ & $n$ \\
\hline 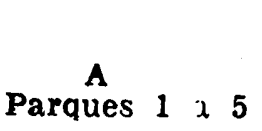 & $\begin{array}{l}\text { Som verdura } \\
\text { Com verdura }\end{array}$ & $\begin{array}{l}5,21 \\
4,77\end{array}$ & $\begin{array}{l}1,80 \\
1,80\end{array}$ & $\begin{array}{l}34,54 \\
37,73\end{array}$ & $\begin{array}{l}0,201 \\
0,146\end{array}$ & $\begin{array}{r}30 \\
150\end{array}$ \\
\hline $\begin{array}{c}\text { B } \\
\text { Parques } 6 \text { a } 10\end{array}$ & $\begin{array}{l}\text { Com verdura } \\
\text { Sem verdura }\end{array}$ & $\begin{array}{l}6,27 \\
6,17\end{array}$ & $\begin{array}{l}1,48 \\
1,48\end{array}$ & $\begin{array}{l}23,60 \\
23,98\end{array}$ & $\begin{array}{l}0,165 \\
0,120\end{array}$ & $\begin{array}{r}80 \\
150\end{array}$ \\
\hline
\end{tabular}

QUADRO 2

Lote $A$ Sem verdura/Com verdura $t=1,76$ Insignif.

Lote B Com verdura/Sem verdura $t=0,50$ Insignif.

Com verdura Lote $A /$ Lote $B$

$\mathrm{t}=-6,82$ Singnif.

Sem verdura Lote $A /$ Lote $B$

$t=-4,17$ Signif.

Como foi díto no decurso da experiência, algumas aves mostraram postora muito irregular, sobretudo as do parque 1, cuja média era'muito baixa comparativamente as demais. Resolvemas pois, fiminar essa fonte de variaçäo proceder nova análise, baselda agora na percentagem de postura em virtude do número de aves variar nos diferentes lotes.

Os resultadás estão encerrados nas quadros 3 e 4 . Os valores de $t$ mostráram-se todos estatisticamente insignificantes, vindo portanto confirmar a análise anterior. A insignificancia entre as lotes, sob o mesmo tratamento, era de se esperar uma vez que as aves de postura irregular foram eliminadas. 


\section{QUADRO 3}

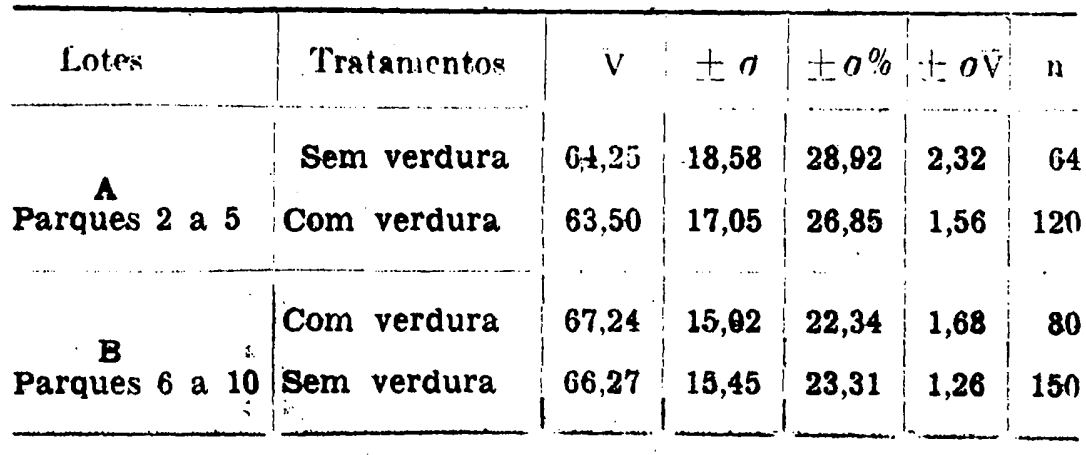

\section{QUADRO 4}

\begin{tabular}{|c|c|c|c|}
\hline Lote A & Sem verdura/Com verdura & $t=$ & Insignif \\
\hline Lote B & Coni verdura/Sem verdura & $t=$ & $"$ \\
\hline Com verdura & Lote $\mathrm{A} /$ Lote $\mathrm{B}$ & $t=-1,633$ & ” \\
\hline Sem verdura & Lote $\mathbf{A}$ /Lote $\mathbf{B}$ & $t=-0,765$ & $"$ \\
\hline
\end{tabular}

\section{3) RESUMO E CONCLUSOES}

A alimentaçáo verde é admitida pelos autores $(3,4,5,6)$ como estimulante do apetite, para boa conservaça "da saude $r$ crescimento das awes, como meio de favorecer a postura $(2,4$, 8). A finalidade unica deste trabalho fol determinăr um possivel aumento ja postura das galinhas em face de uma alimentação verde abundante. Foram reunida 100 avès è grupos de 10 para cada parque, constituindo os numeros 1 a 5 o lote $A$ $c$ os de númezo 6 a 10 , o lote $B$.

A experiencia iconstou de 2 periodos : o primelro (16 dias) no qual o lote $A$ sofreu um tratamento sem verdura $e$ o lote $B$, com verdura. No segundo periodo ( 30 dias) inverteram-se os 
tratamentos. A ração utilizada foi a mesma durante a experiencia, uma vez que interessava saber qual a influência da alimentação verde na postura, năo se cogitando aqui, a influencia dêsse tratamento, sóbre a geminabilidade dos ovos ou sanidade das aves.

Do exposto acima, foram realizadas análises e chegou-se às seguintes conclusões :

1) Admitindo todos os parques $\rightarrow$ de n. ${ }^{\circ}$ 1-5 para o lote A e de n. ${ }^{\circ}$ s 6-10 para o lote $B$ - incluindo portanto todas as aves que compunham cada parque, independente de uma postura irregular, concluimos : a) 0 tratamento com verdura para ambos os lotes năo trouxe aumento da postura; b) as 2 lotes oram diferentes.

2) Suprimindo o parque N.० 1 do lote $A$ por apresentar uma média de postura muito baixa e ainda tódas aves dos demais lotes que apresentaram no decorrer da experiencia postura irregular, concluímos: a) no tratamento com verdura nảo houve, aqui também, aumento da postura; b) os 2 lotes mostraramse iguais, como era de se esperar, uma vez que fizemas uma elíminação prévia das poedeiras irregulares.

Assim pela observaçấo dessas duas análises, chegou-se a uma conclusão final que a alimentação verde náo trouxe aumento da postura e portanto poderá ser dispensada para tal fim, porém năo duvidamos que para aves submetidas a raçóes deficientes em certos elementos, como vitamina A, certos ánimos ácidos, esta modalidade de tratamento poderá apresentar vantágens. Partindo como de início relatámós, de grupos de aves já adultas e submetidas a uma raçáo completa chegámos à conclusão acima. O tempo de duração da experiência foi muito curto para se poder constatar uma carência de vitaminas, que poderiam estar armazenadas, porém tal defeito da raçáo dependeria exclusivamente dos ingredientes que concorrem na formação da falèlada. Está cónstatado por exemplo, que sob uma ração em que entre $50 \%$ de milho amarelo, nă se 'nota avitaminose A. Eevidente, que quanto mais desequilibrada fôr a ração, maior será a necessidade de suplementaçáo de verde. $\because$

\section{4) AGRADECIMENTO}

QS autores agradecem ao prof. A. Di P. Torres e Dr. E. A. Graner pelas sugestōes e criticas formuladas. 


\section{5) ABSTRACT}

A lest was conducted at Poultry Department of "Luiz de Queiroz" School of Agritulture to prove the effect of green feed on egg production.

One hundred Rhode Island Red hens at plain laying period were div:ded in ten pens. The lot $A$ was constituted of pens 1 to 5 and the lot $\mathrm{B}$ of pens 6 to 10. During 16 days the upens 1 to 5 did not receive green feed and the pens 6 to 10 received it with abundance. After and for a period of 30 days the situation was inverted.

The analysis were made considering. a) the production of all chickens and b) discarding the chickens with irregular laying. In both cases the results were statistically insignificant, proving thất green feed did not improve egg production.

\section{6) BIBLIOGRAFIA}

1) BRTEGER, F. G. (1937) Tábua e fórmulas para estatística. Cia. Mẽlhoramentos de S. Paulo.

2) BLANCHON \& DELMARRE DE MONCHAUX (1924) Toutes les poules.

3) CARD. L. E. (1932) Feeding for egg prodution. University of Illinois. Circular N.0 275.

4) DURIGEN, B. (1931) Tratado de Avicultura. Gustavo Gili, Barcelona. (traduçáo espanhola da 5.a edição alemã).

5) LAMON \& LEE (1929) Poultry feeds and feeding.

6) MORRISON, F. B. (1943) Feeds and Feeding.

7) ROBERTSON GEORGE (1936) Poultry feeds and feeding. Dominion of Canadá. Department of Agriculture. Publ. 541.

8) SANTOS EURICO. Avicultura, fonte de riqueza. 